\title{
14 How Does Phenotypic Plasticity Fit into Evolutionary Theory?
}

\author{
Douglas J. Futuyma \\ Stony Brook University
}

Phenotypic plasticity, in the broadest sense, has been recognized in evolutionary biology since its inception, but like several other important topics, became a major focus of inquiry and theory only in the 1960s and 1970s. The question posed in my title requires a historical approach. I will trace the history (as I understand it) of interpretation and research on phenotypic plasticity in evolutionary thought, emphasizing antecedents of today's interpretations, debates, and research, especially on the role of plasticity in trait evolution.

Darwin was very aware of the distinction between inherited variation and that caused by "the direct action of the physical conditions of life" (Darwin 1996 [1859], p. 376), and, as is well known, he acceded slightly to Lamarck's doctrine in the later editions of The Origin of Species (see Costa 2021 in this volume). The first substantive attention to plasticity that resonates today was the independent proposition in 1896, by James Baldwin, Lloyd Morgan, and H. Fairfield Osborn, of what Simpson (1953) would later call the 'Baldwin effect.' Simpson interpreted this to be the evolutionary phenomenon whereby "characters individually acquired by members of a group of organisms may eventually, under the influence of selection, be reinforced or replaced by similar hereditary characters" (Simpson 1953). I shall follow Simpson's use of the term 'Baldwin effect,' although other interpretations are possible (West-Eberhard 2003, p. 24; Crispo 2007).

During the earliest days of Mendelian genetics, variation attributable to genotype, environment, and their interaction became clarified. Woltereck (1909) introduced the concept of a genotype's norm of reaction, the array of phenotypes a genotype can produce under different environmental conditions - and thought it could be adaptive. Turesson (1922) recognized habitat-associated forms of many plant species that he called ecotypes, by which he meant "the product arising as a result of the genotypical response of an ecospecies or species to a particular habitat" (Turesson 1922, quoted by Stebbins 1950, p. 42). He and many later botanists, motivated largely by the need to clarify species taxonomy, developed the common-garden method of distinguishing genetic and nongenetic variation. Based on their common-garden study of several species, Clausen et al. (1940) concluded that both heredity and 'modification' 
by the environment contribute to differences among species, 'races,' and individuals within populations. They concluded that regional 'races' are heritably distinct ecotypes, not 'modifications,' and that ecotypes generally "are unable to succeed in conditions very unlike those of their native environs." They did not address the adaptive importance of any of the specific features they measured, nor which features might underlie the ecotypes' fitness in native or foreign environs.

Turesson (1922) emphasized that 'modifications' may closely resemble heritable variations. Richard Goldschmidt (1935), now known mostly for his unfortunate ideas about macroevolution, discovered 'phenocopies:' environmental modifications of the phenotype that resembled specific gene mutations. The important conclusion is that specific developmental pathways can be affected similarly by genetic or environmental perturbations. This understanding underlies Waddington's (1942) argument that natural selection builds up 'canalization' of an adaptively important character, buffering it against both genetic and environmental alteration.

In the founding works of the Evolutionary Synthesis, phenotypic plasticity was discussed only marginally. Dobzhansky, in the first edition of Genetics and the Origin of Species (1937), referred to the work of Turesson, Clausen et al., and Goldschmidt, and emphasized that "what is inherited...is not this or that morphological character, but a definite norm of reaction to environmental stimuli" that differs between 'wild type' and mutants. In the third edition of his book (Dobzhansky 1951), he drew repeatedly on the views of Schmalhausen (1949), who extensively discussed norms of reaction, shaped, he wrote, by stabilizing selection. Bernhard Rensch (1947, 1959) noted (p. 26) that "Modification [by environment] and mutation often act in the same direction, giving similar phenotypic results (phenocopy)..." In Variation and Evolution in Plants (1950), Stebbins wrote that “...in some species natural selection has favored a high degree of phenotypic plasticity in terms of environmental modification, in spite of the low heritability and consequent inefficiency of selection which this brings about" (p. 106). This last phrase, conveying the view that plasticity is likely to reduce the response to selection, was also expressed by Wright (1931), Mayr (1963), and others.

Attention to plasticity increased in the 1950s. For example, Thoday (1953) contrasted developmental and behavioral plasticity. Genetic and nongenetic variation were important to plant and animal breeders, and many experiments with model species (Drosophila, Mus) had implications for understanding variation in both domesticated and natural populations (cf. Falconer [1981]). In a symposium on this theme, Mather (1955) emphasized that environmental variance in a character could signal either adaptive plasticity or nonadaptive instability. Perhaps most important, and most relevant to current concerns, were Waddington's experiments and ideas about canalization and genetic assimilation (Waddington 1942, 1952, 1953a,b). Waddington, like Schmalhausen, proposed that stabilizing selection for an optimal phenotype would result in the evolution of canalization, whereby phenotypic effects of environmental (or genetic) perturbations are minimized (see Scheiner and Levis 2021 in this volume). Sufficiently strong, perhaps novel environmental or genetic perturbations of development may exceed a canalization threshold and reveal phenotypic variation. If this variation has a genetic component, selection can act to 
favor a different mean phenotype that, in turn, can become canalized-in which case it appears that an environmentally induced phenotype has become inherited, or 'genetically assimilated.' In one experiment, Waddington acted on his observation that a heat shock during pupal development resulted in Drosophila adults with an interrupted crossvein in the wing. By breeding from flies that showed the most pronounced effect of the heat shock, he eventually produced a lineage that lacked the crossvein even without heat shock. He interpreted the result to mean that many genes affect the susceptibility of vein development to this environmental stimulus.

This idea-that a phenotypic state expressed at first in response to an environmental stimulus may become more genetically determined-is much the same as Simpson's description of the 'Baldwin effect;' Simpson's Baldwin effect and Waddington's genetic assimilation are much the same hypothesis, for all practical purposes. In some of today's literature (e.g., Chevin and Hoffmann 2016; Scheiner et al. 2017), two kinds of loci are envisioned: those with a fixed effect on a trait (i.e., a flat norm of reaction) and those with a plastic effect (lending a nonzero slope to the reaction norm). Genetic assimilation is the replacement of plastic allelic effects with fixed effects.

Although Waddington's genetic assimilation is often thought to challenge the Evolutionary Synthesis, I have been impressed by how little it seems to have bothered adherents to the traditional view. Mayr (1959) accepted Waddington's interpretation of his experiment on the crossveinless phenotype: "We are here simply dealing with a threshold phenomenon where numerous genes contribute to a certain phenotype but where the potentiality for it will not be pushed above the visible threshold until a sufficient number of genes have accumulated in the genotype" (Mayr 1959). Dobzhansky (1970) accepted that 'canalizing selection' can result in traits that show little or no variation, but can be selected when variation is revealed by an environmental change (citing the crossveinless experiment) or by a genetic mutation. For example, the number of scutellar bristles (four) is highly canalized in Drosophila but is variable in strains with the scute mutation. In such stocks, the number of bristles can be altered by selection (Rendel 1959), and selection can increase or decrease the feature's temperature-dependence (Kindred 1965). In his very influential book on quantitative genetics, Falconer (1981) cited Waddington's work in his discussion of threshold characters, which had been known at least since Sewall Wright's early research on guinea pigs. These studies and others (e.g., Milkman 1964) made canalization and robustness a live topic in the 1960s, but it then largely disappeared until the late 1990s (see Wagner et al. 1997; Hermisson and Wagner 2004; de Visser et al. 2003).

Leading evolutionary biologists, then, did not doubt that genetic assimilation was compatible with the synthetic theory of evolution; the question, rather, was whether or not it has often played a role in evolution. Simpson (1953) wrote that all of the processes that underlie the Baldwin effect are known to occur, that there is no reason to doubt that they could co-occur, that "there is even some probability that they must have produced that effect sometimes," and that "the Baldwin effect is fully plausible under current theories of evolution." He noted that Julian Huxley, in Evolution: The Modern Synthesis (1942), accepted it and invoked it to explain 
early stages of population divergence, such as host races of some herbivorous insects. Although Simpson accepted the Baldwin effect as a theoretical possibility, he questioned whether it explains any particular instances of evolutionary change, and whether it has been common and explains adaptation in general. He concluded that "the Baldwin effect [is]...well worthy of further study. It does not, however, seem to require any modification of the opinion that the directive force in adaptation, by the Baldwin effect or in any other particular way, is natural selection" (Simpson 1953, p. 116).

To the question, "how do the Baldwin effect and genetic assimilation fit into evolutionary theory?", the answer seems to be "comfortably enough that they could be tolerated, even if not welcomed as the solution of a thorny problem." If anything, they might have been considered a plausible solution in search of a problem.

Phenotypic stability, inconstancy, and plasticity became an increasing focus in field and experimental studies of plants and Drosophila in the 1950s and 1960s. Anthony Bradshaw (1965) magisterially reviewed and interpreted much of this work, especially in plants, citing evidence that plasticity varies among characters and among related species, populations, and genotypes; that character stability can be decreased or increased by artificial selection, "perhaps most elegantly demonstrated by Waddington's genetic assimilation studies" (cf. also Reeve 1960, Prout 1962); and that adaptively important characters are developmentally more stable than less important ones. (For example, he cited Mather's [1953] finding in Drosophila that the coefficient of variation was ten times greater for bilateral asymmetry in the number of sternopleural bristles than for asymmetry of wing length.) He reviewed cases of clearly adaptive plasticity, as well as evidence that under stabilizing selection, plasticity can result in phenotypic uniformity that masks genetic variation. (For example, he cited a study of Plantago maritima, which was phenotypically uniform in the field but variable in an environmentally more uniform experimental garden [Gregor 1956].) Bradshaw identified some 'open problems,' including the mechanistic basis of discrete versus continuous plasticity, the mechanisms by which different plastic traits covary, and especially, how much genetic variation for plasticity exists in natural populations, and how responsive it is to natural selection.

Phenotypic plasticity attracted more research effort in the 1980s. In a review of "the evolution of phenotypic plasticity in plants," Schlichting (1986) argued that a character and its plasticity may be under somewhat separate genetic control and could therefore evolve independently. In that case, phenotypic plasticity might not inhibit character evolution. He cited evidence (e.g., Scheiner and Goodnight [1984] in the grass Danthonia; Stearns [1983] in Gambusia mosquitofish) that "plastic traits do not necessarily evolve less." Since then, genome-based analyses have shown that, at least in Drosophila, largely different genes control the value of a trait and its plasticity (Ørsted et al. 2017; LaFuente et al. 2018, 2019).

The 1980s saw a profusion of relevant theory, studies of the quantitative genetics of reaction norms, and focus on plasticity as a common adaptation to temporal or spatial variation in environment (reviewed by Scheiner 1993). Optimality models were developed especially for life history traits (e.g., Stearns and Koella 1986; Moran 1992). Quantitative genetic models by Lynch and Gabriel (1987), Gavrilets 
and Scheiner (1993), and others showed that plasticity is likely to be favored if it has low fitness cost and if different environmental states are equally frequent, impose strong selection, and are reliably cued. Via and Lande (1985) introduced an influential quantitative genetic model, in which phenotypes expressed in different environments are treated as genetically correlated traits. This seemed to call into question of whether plasticity should be viewed as a genetically variable character in itself that may be the direct target of selection (Schlichting and Piglucci 1998). The recent evidence that genetic variation in plasticity and in the trait mean can be independent suggests that plasticity can be considered a character if that is useful for questions about the evolution of reaction norms.

Since the 1980s, considerable research has confirmed that many plastic responses are adaptive. In many cases, as in the foraging behavior of birds or the growth patterns of plants in sunlight and shade, the adaptive value of plasticity is almost selfevident. In some cases, traits vary as predicted by theory, such as paedomorphosis in Ambystoma salamanders (Semlitsch et al. 1990), offspring sex ratio in parasitoid Nasonia wasps (Orzack 1986), and heterophylly in aquatic versus terrestrial Ranunculus buttercups (Cook and Johnson 1968). Nevertheless, patterns of plasticity do not always meet our perhaps naïve expectations. For example, variation among Drosophila species in phenotypic plasticity for heat tolerance is only weakly correlated with the thermal regimes they experience in different geographic regions (Overgaard et al. 2011).

The 1980s were also a period in which the evolution of ecological specialization and generalization became a research focus. Phenotypic plasticity, of one kind or another, would be expected to underlie greater niche breadth, whereas habitat or diet specialists might be less plastic (Futuyma and Moreno 1988; van Tienderen 1991). Futuyma and Moreno (1988) noted that populations with broader niches usually are composed of broad-niched, flexible individuals, rather than sets of specialized morphs: the 'between-phenotype' component of niche width (Roughgarden 1979; Taper and Case 1985) is usually small. They found that ecological specialists sometimes, but not always, display narrower physiological tolerances or efficiency of resource use.

Having become a focus of research programs in the 1980s, phenotypic plasticity has since enjoyed a large, diverse literature. A fundamental question is whether or not it increases fitness. Despite many examples like those I have cited, formal selection analyses have been more equivocal. Van Buskirk and Steiner (2009) and Arnold et al. (2019) reviewed studies that estimated selection on plasticity and found that positive and negative selection gradients were both common. A critical question is how to determine if an instance of phenotypic plasticity is an adaptation that has been built by natural selection in the environment in which it is manifested, or evolved in a very different context, or is a 'side effect' of development that only incidentally happens to increase fitness in a certain environment (Fox et al. 2019).

The nature and consequences of costs and limits of plasticity have also been an important topic (DeWitt et al. 1988; see also Snell-Rood and Ehlman 2021 in this volume). It is important to distinguish between the fitness cost of a particular phenotypic state and the cost of maintaining the underlying ability to produce that 
phenotype or others: the cost of plasticity as such. Van Buskirk and Steiner (2009) and Murren et al. (2015) reviewed relevant studies, found rather little evidence of plasticity costs, and concluded that they are hard to demonstrate. In contrast, SnellRood et al. (2018) describe a wide array of costs and argue that plastic responses are costly, especially as manifested by cases of 'developmental selection' (trial-anderror exploration, as by plant roots that may find water or nutrients in some places but not others). Some causes of a plasticity cost, such as maintenance of a potential developmental trajectory, might be hard to detect; others, such as developing an inappropriate phenotype because of an undependable environmental cue, might be easier.

Much recent research and discussion pertains to the evolutionary consequences of plasticity. I will mention four possible consequences: the effect of plasticity on responses to selection, the consequences of maladaptive plastic responses, the role of plasticity in averting extinction, and its role in the evolution of new or modified phenotypic traits.

An important question is, does plasticity reduce the genetic response to directional selection? A contrary view is that plasticity allows the increase of cryptic genetic variation that might be expressed when exposed by environmental stress (Paaby and Rockman 2014). That is, plasticity might serve as a 'genetic capacitor' (Rutherford and Lindquist 1998; see also Schlichting 2008). In a genetic network model, Draghi and Whitlock (2012) described a trait that evolves plasticity, accumulates greater genetic variance, and enhances evolution along the axis of plastic phenotypic variation. Based on a meta-analysis of relevant studies, Noble et al. (2019) concluded that plastic responses to different environments are, indeed, fairly well aligned with phenotypic dimensions that are highly genetically variable. They note, however, that this makes it difficult to distinguish a 'plasticity-led' evolved difference between populations from genetic constraint: evolution along the genetic line of least resistance (Schluter 1996).

Perversely, genetic evolution can also be provoked by maladaptive plasticity, as illustrated by instances of countergradient variation, in which the direction of genetic differences between populations is opposite to environmental effects on the phenotype (Conover and Schultz 1995). Grether (2005) termed such evolution 'genetic compensation.' For example, Ghalambor et al. (2015) found that guppy populations transplanted from streams with cichlid predators to cichlid-free streams evolved changes in the expression of many genes in the brain - and that most of these showed the opposite plastic change when fishes in the source population were reared in the absence of predators. Likewise, plastic changes in gene expression that occurred in experimental populations of yeast and Escherichia coli were mostly maladaptive, since they were generally counteracted by genetic changes that reversed the expression level back toward its original state (Ho and Zhang 2019). Maladaptive plastic changes may deserve considerable further study.

A third current question concerns the role of phenotypic plasticity in rescuing populations endangered by environmental change, such as anthropogenic climate change (see Diamond and Martin 2021 in this volume). In the first of several papers, Lande (2009) modeled adaptation to a sudden drastic environmental change in a 
population that has a genetically variable reaction norm, but with little expressed $G \times E$ variation, due to stabilizing selection. The environmental change reduces mean fitness which, however, rapidly increases due to plasticity, up to some limit. In the new environment, plasticity evolves so that the mean phenotype reaches a new optimum, which is slowly fixed by genetic assimilation due to stabilizing selection. (Note that Lande, a strong adherent to the Evolutionary Synthesis, accepted genetic assimilation as an evolutionary process.) Chevin et al. (2010) followed with a model of evolution in a gradually changing environment and found that although plasticity reduces the rate of genetic evolution by weakening natural selection, "this is more than compensated by the plastic change that brings the phenotype closer to the optimum" (p. 5). They noted, though, that extreme, stressful environments may disrupt the phenotypic response, as such environments will have been rarely encountered in the past, and so will have exerted little selection (cf. Hoffmann and Parsons 1991). Chevin and Hoffmann (2017) emphasized that plasticity is likely to rescue populations under new extreme conditions only if the phenotype expressed in the extreme environment (e.g., very hot) is genetically correlated with the expression in the ancestral environment (warm or moderately hot). There are few data on such genetic correlations.

Research on the role of plasticity in averting population extinction is increasingly important, as we recognize how drastic the effects of human activity are. For example, as spring has shifted earlier with global climate change, many temperatezone bird species have shifted their nesting and egg-laying dates, and so have tracked resource peaks and avoided excessively high temperatures (Phillimore et al. 2016; Socolar et al. 2017). However, species that breed in the temperate zone but overwinter in the tropics have no information on the beginning of suitable nesting conditions, so plastic responses are of no avail. Their arrival and nesting are mistimed, and some such species have suffered population declines (Both et al. 2006; Mayor et al. 2017). Plasticity is not always an adaptive option.

Surely the most prominent and controversial current question about phenotypic plasticity concerns its role in evolutionary change of traits. (This is often expressed as the evolution of 'novel' traits, but I will restrict 'novel,' as does Wagner [2014], to the origin of a new character, a trait that is not simply a quantitative change in a preexisting trait.) This topic was greatly enlivened by the publication of West-Eberhard's extraordinarily comprehensive tour de force, Developmental Plasticity and Evolution (2003), which expanded on and sharpened her earlier treatments of the topic (e.g., West-Eberhard 1986, 1989). West-Eberhard proposed that many fixed, species-typical features represent part of a plastic ancestral reaction norm that has been 'genetically accommodated.' 'Genetic accommodation' was broadly defined and can include genetic assimilation, modification of the expressed trait, or evolutionary changes in other traits that interact with the focal trait. Most subsequent discussion has concerned that aspect of genetic accommodation that is tantamount to genetic assimilation. This is now an active topic, which I treat very briefly.

West-Eberhard, like earlier authors such as Goldschmidt and Waddington, noted that the development of a trait may react similarly to mutational or environmental 
perturbations. Recurrence of the perturbation produces a subpopulation of individuals that express the trait, affording the opportunity for gene-frequency change due to selection on its expression (p. 140). Although recognizing that either genetic or environmental perturbation initiates this evolutionary process, West-Eberhard devoted much of the book to her view that environmental initiation is more important by far, and drew on an extraordinary range of information to develop her argument. The critical reactions of some traditional evolutionary biologists (e.g., de Jong and Crozier 2003) may have been influenced by her colorful, sometimes challenging, statements like this often-quoted passage: “...most phenotypic evolution begins with environmentally initiated phenotypic change...Gene-frequency change follows, as a response to the developmental change. In this framework, most adaptive evolution is accommodation of developmental-phenotypic change. Genes are followers, not leaders, in evolution" (pp. 157-158).

My own reactions to Mary Jane's thesis were cautious. (I should say that I had the good fortune of being a fellow graduate student with her, then as now an awesomely creative biologist, outstanding naturalist, and friend.) Recall Simpson's (1953) judgment of the Baldwin effect: he said it is fully compatible with modern evolutionary theory, but asked for evidence that it occurs in natural populations, or that "it is a frequent and important element in adaptation." So did I.

West-Eberhard's examples of possible cases of evolution by genetic accommodation of environment-induced phenotypes could easily be matched or exceeded by straightforward examples of a genetic basis for characters that distinguish populations and closely related species. And in writing several editions of an evolution textbook, I had sought in vain clear examples of genetic assimilation in nature. (Carl Schlichting and I discussed this point at an evolution meeting, about 15 years ago. Neither of us knew of a convincing example at that time.) What was necessary, I felt, was historical evidence, perhaps from phylogeny, that a relatively invariant trait in one population had evolved from a broader norm of reaction, a more plastic ancestral trait as seen in another population. West-Eberhard (p. 204) discussed the importance of establishing the polarity of evolutionary change, but most of the examples in her book did not provide the historical element. de Jong and Crozier (2003) wrote that West-Eberhard had failed to show that developmental plasticity is "the initiating factor of adaptive novelty, preceding genetic change."

More recently, a number of phylogenetically supported cases of evolution by genetic assimilation and abbreviation of ancestral phenotypic plasticity have been described (see Scheiner and Levis 2021 in this volume). In an early review, Schwander and Leimar (2011) cited several cases in which conditional alternative phenotypes have been lost, as in one of the worker castes of certain ants and the development of horns in some species of Onthophagus dung beetles (Moczek et al. 2006 and later papers).

Some studies have provided more detailed analyses of evolutionary changes by genetic assimilation of an ancestrally plastic condition. A carefully documented example is the fixation of an amelanic phenotype, which ancestrally develops only under low ultraviolet light, in populations of Daphnia that experienced increased 
exposure to predatory fish (Scoville and Pfrender 2010). In a rather similar case, a population of the side-blotched lizard (Uta stansburiana) on a lava flow is much darker than other populations that live on sand. Individuals of both forms become darker if kept on sand for a year, but lava-population lizards become darker than sandpopulation individuals. The difference was attributed to recently derived, positively selected variants in two genes that regulate the melanogenesis pathway (Corl et al. 2018). The authors noted its conformity to the Baldwin effect. In female Drosophila melanogaster, temperature-dependent development of abdominal pigmentation is due largely to modulation of histone marks in a promoter of the tan gene, and a lossof-function mutation in this enhancer appears to underlie the fixed expression of pale coloration in the related species D. santomea (Gilbert 2017).

All of these cases represent not the origin of a feature, but instead an extension or an abbreviation of a broader ancestral reaction norm. Among the several examples that support the 'plasticity-first' view of evolution (see Levis and Pfennig 2021), few purport to explain the origin and evolution of what I consider novel traits, such as multi-cusped teeth (in ancestors of mammals), branched body hairs (of bees), or tubular corollas (of many plants). To be sure, the genetic and developmental origins of most novel traits are poorly understood; see Wagner (2014). And the distinction between 'novel' and 'highly modified' traits is fuzzy. In the great adaptive radiations of African cichlids, for example, some of the trophic variation among species is attributable to functionally important differences in the form of the pharyngeal jaws and the teeth they bear. As West-Eberhard (2003) describes, some of these differences arise among conspecific individuals that are reared on different diets - phenotypic plasticity that might have played a role in the evolution of adaptive trophic diversity.

Another possible example of a role for plasticity in macroevolutionary novelty concerns the origin of tetrapod vertebrates (see also Lister 2021). Bony fishes are divided into two clades, the diverse ray-finned fishes (Actinopterygii) and the lobe-finned fishes (Sarcopterygii), from which tetrapods evolved. Bichirs (Polypterus) are a basal clade of ray-finned fishes that are semiterrestrial, using their pectoral fins to crawl on land, as long as they can stay wet and breathe. Compared to individuals that developed in water, individuals that were raised on 'land' used their fins more effectively and showed modest alterations of the pectoral girdle that parallel those seen in some Devonian stem tetrapods (Standen et al. 2014). Whether or not this is evidence of a role for plasticity in tetrapod origins is hard to say. Because environmental and genetic perturbations of a developmental pathway can have similar effects (Noble et al. 2019), the bichir experiment may illustrate coincidence of similar developmental responses, rather than bearing on the actual historical origin of tetrapod features. This seems especially likely because bichirs are not closely related to tetrapods, but in general, satisfying de Jong and Crozier's criterion-showing that there has been a historical shift from a plastic reaction norm to a fixed character state-is a challenge.

This challenge is most likely to be met by information on closely related populations or species (cf. Levis and Pfennig 2016). In well-documented cases, a key question is how the ancestral reaction norm originated. Ghalambor et al. (2007) 
and others have pointed out that plasticity is most likely to play a role in adaptive evolution if the ancestral reaction norm happens to be directed more or less toward the new phenotypic optimum. Plasticity is less likely to enhance genetic adaptation if it is nonadaptive (as in developmental instability) or if it is maladaptive (as in the common phenomenon of countergradient variation) (Conover and Schultz 1995; Grether 2005; Storz and Scott 2019). The plastic ancestral reaction norm is likely to be aligned with the direction of selection in a new environment that is not entirely novel but is more or less an extension of the ancestral environment (Pigliucci 2010; Snell-Rood et al. 2018), and if the phenotypic states expressed in ancestral and new environments are genetically correlated, as Chevin and Hoffmann (2016) emphasized. A somewhat higher temperature is more likely to be met by a suitable plastic response than a novel chemical such as DDT or thalidomide. (This was a drug prescribed for pregnant women in the 1950 s, that resulted in thousands of children's being born with shortened limbs and other deformities.)

In many postulated cases of 'plasticity-led evolution,' the phylogenetically derived state appears to be a modification of adaptive rather than non- or maladaptive plasticity. This is clearly true of cases in which the ancestral reaction norm has been simply abbreviated, reduced to expression of only one of the ancestrally possible expressions (e.g., neoteny in salamanders, fixation of the less melanized state in Daphnia and in Drosophila santomea, loss of horns in Onthophagus). The evolutionary scenario is one in which: (1) natural selection acting on genetic variation in reaction norms has shaped adaptive phenotypic plasticity; (2) later, selection on genetic variation in this adaptive reaction norm shapes a phenotype that is less plastic and more genetically canalized. Adaptive evolution is still ultimately a matter of natural selection and genetic variation, the central model in the Evolutionary Synthesis. But genetic assimilation of an advantageous plastic phenotype is by no means certain. Scheiner et al. (2017) simulated evolution when there exists genetic variation for both fixed and plastic effects on a phenotype. Adaptation to a new environment can occur by increased plasticity if the cost of plasticity is low, but is more likely to evolve by the increase of fixed-effect alleles if plasticity is costly or has only small phenotypic effects. If adaptation does occur by plasticity, genetic assimilation-replacement of plasticity alleles by fixed-effect alleles-occurs only if plasticity is costly, but even then, it occurs very slowly (as also found by Chevin et al. 2010; see also discussion in Scheiner and Levis 2021).

Because there is hardly any challenge to standard theory when derived characters are a fixed state of an advantageous ancestral reaction norm, I find most interesting several cases in which the ancestral state seems not to have been an adaptive reaction norm. Aubret and Shine (2009) showed that greater head size of juvenile tiger snakes (Notechis scutatus) is advantageous in island populations, where prey are large. In populations on recently colonized islands, juveniles develop larger heads if they are fed larger prey, but this plasticity is lower in older island populations. The authors attribute this to genetic assimilation. But the peculiar feature of this study is that the mainland source population does not exhibit plasticity in head size; it appears to have 
evolved rapidly, de novo, in island populations. The authors noted that "this aspect is not predicted by current evolutionary models."

Another curious case is afforded by the 'carnivore morph' of larval spadefoot toads in the genus Spea, described by Pfennig and his collaborators (Ledón-Rettig et al. 2010; Levis et al. 2018), which displays several features that are induced by feeding on animal prey. The more common 'omnivore' morph, which feeds on detritus, resembles in diet and form the larvae of the sister genus, Scaphiopus, as well as more distantly related genera, in which detritus-feeding is the ancestral habit (Ledón-Rettig et al. 2010). Surprisingly, Scaphiopus larvae that were fed shrimp developed some features of the carnivore morph, such as a shorter gut, despite no suspected history of having experienced selection for this developmental response. The developmental response seems not to be an adaptation, even though it can have an advantageous effect.

Are cases such as these odd, rare 'accidents' of development, rare enough to count for little, or are such instances common and in need of explanation? Much of the argument for the evolutionary role of phenotypic plasticity in trait evolution describes evolutionary modifications of supposedly ancestral plastic phenotypes, yet seems not to burrow into the origin of those ancestral reaction norms themselves. If development and phenotypic plasticity are to play the truly fundamental, creative role that some adherents to the 'extended evolutionary synthesis' claim (Laland et al. 2015), it will be in cases that are not ascribable simply to selection on genetically variable plasticity that is itself a result of natural selection.

As I emphasized, major figures in the Evolutionary Synthesis and since found evolution by genetic assimilation and canalization quite compatible with their theory of evolution; they questioned only how common it might be. It seems that it has occurred more frequently than we knew and poses a range of questions that can't fail to enhance our understanding of evolution. Many of these questions will require understanding processes of development, and how genes are regulated and exert their developmental effects. Some of these processes will undoubtedly be surprising and will call for evolutionary explanation, just as some molecular processes did (e.g., transposable elements, alternative splicing).

One such process is transgenerational phenotypic plasticity, whereby a parent's environment affects the phenotype, and often the fitness, of the offspring (see discussion in Bonduriansky 2021 and Pfennig 2021 in this volume). This has emerged as a second point of current controversy about phenotypic plasticity, even though environmental maternal effects have long been known, are often adaptive, and have been treated in evolutionary models (e.g., Mousseau and Fox 1998; Wolf et al. 1998; Kirkpatrick and Lande 1989; Lande and Kirkpatrick 1990). Nongenetic paternal effects have also been described in diverse species (e.g., host-plant responses in leaf beetles, Futuyma et al. 1993). They can affect diverse traits, and in some cases, they increase offspring fitness (Crean et al. 2013; Schmid and Dolt 1994). Imprinting and other epigenetic mechanisms seem likely to underlie many cases of transgenerational plasticity and other instances of inheritance that are not based on DNA sequence variation (Lawson et al. 2013; Bonduriansky and Day 2009, 2018). This form of 'extended heredity' does depart substantially from the heredity known 
during and for several decades after evolutionary synthesis, and undoubtedly will add significantly to evolutionary theory.

As nongenetic inheritance and phenotypic plasticity are prominent planks in the platform of the 'extended evolutionary synthesis' (Pigliucci and Müller 2010; Laland et al. 2015), I end with some thoughts on how they may fit into the history of evolutionary biology (see also Futuyma 2015, 2017). The core theory of the evolutionary synthesis, framed in terms of the effects of mutation, gene flow, genetic drift, and especially natural selection on the frequencies of alleles and genotypes, has been a grandly successful theory because it is so general, encompassing any trait you might think of. It is silent about what the trait might be: a morphological character, a life history feature, an enzyme, a doubling of the genome. During and ever since the Synthesis, theoreticians, naturalists, and experimentalists have been amplifying and particularizing the theory to describe the evolution of real traits: life histories; cooperation, conflict, mate choice and other behaviors; genes and then genomes; physiological tolerances; ecological specialization; geographic range limits; and much more. The evolutionary theory developed for these classes of traits requires knowledge of their function and, ideally, mechanistic development. For some of these classes of traits, other biological disciplines have described previously unknown mechanisms and processes that have become explananda for evolutionary biology; many have been successfully explained; and the union of biological mechanism with evolutionary explanation, the union of proximate and ultimate causes, has expanded evolutionary biology. (Evolutionary genomics is perhaps the most striking example.) Phenotypic plasticity and extended heredity follow this historical path; they are currently among the subjects that both look for further explanation and contribute to the continuing expansion of evolutionary theory.

Perhaps it need not be said, but it remains important to eschew any hint of vitalism. There is no reason to suppose that organisms are endowed with an inherent ability to react advantageously to perturbations and stresses. It remains true that most mutations that affect fitness are deleterious, as are many or most novel changes in environment. (The vast majority of species are extinct.) Plastic compensatory responses of individual organisms, that mitigate harmful effects, are not inherent in living things; they have evolved (Kirschner and Gerhart 2005). So, if a phenotypically plastic capacity provides a foundation for an advantageous, genetically accommodated character, that plasticity itself requires explanationand the explanation will often, or usually, be our old friends, genetic variation and natural selection. Many nonbiologists may welcome theories such as Lamarckism instead of natural selection, for, as the historian of science Peter Bowler (1989, p. 258) wrote, "Lamarckism allows life itself to be seen as purposeful and creative. ...Life becomes an active force in nature, no longer merely responding in a passive manner to environmental pressures." As scientists, we do not succumb to that seduction. Of course, the evolved characters of a species-including various forms of plasticity, even human cognition that conceives of purpose-do influence its effective environment and selective pressures. But it's still genes and selection, all the way down. 


\section{BOX 14.1 SUGGESTIONS FOR FUTURE RESEARCH}

- Do ecologically generalized species have greater plasticity in key traits than related specialists? And does this make generalist lineages more 'evolvable' than specialists? For example, there is evidence that gene families associated with chemoreception, detoxification, and digestion are larger in generalist than specialist herbivorous insects (Calla et al. 2017; Pearce et al. 2017; Cheng et al. 2017). Do generalists have a greater capacity than specialists to evolve new host-plant associations (Janz and Nylin 2008; Hardy 2017; Nosil and Mooers 2005)? How do these questions apply in other aspects of niche evolution?

- Waddington's classic experiments on genetic assimilation were based on unusual stresses, such as heat shock, rather than an accentuation of an environmental change that had exerted selection for phenotypic plasticity. Are there any examples in which adaptive evolution based on phenotypic plasticity can be ascribed to novel stresses of this kind? (cf. Hoffmann and Parsons 1991.)

- Compared to populations that experience less variable environments, do related populations in more variable environments display both greater phenotypic plasticity and greater additive genetic variance for relevant traits?

- Noble et al. (2019) note that it can be difficult to distinguish plasticityled evolution from genetically constrained evolution if plasticity and genetic variation are aligned in 'phenotype space.' Are they often aligned? If so, are there solutions to this dilemma? Might molecular characterization of the relevant genes and their regulation answer these questions?

- If we compare an array of characters in related populations and species, do divergent characters display greater plasticity than characters that have not diverged? Is the plasticity, if present, aligned with the direction of divergence? Is there a difference between multidimensional characters (perhaps coloration) and unidimensional traits (perhaps measures of body size)?

- How diverse are the features for which 'plasticity-led evolution' might be suspected? How about, in angiosperms, flower structure, the form and density of trichomes, leaf shape, margin, and venation, drought tolerance? Sexual and social display characters in insects, fishes, birds? Lepidopteran wing patterns, gastropod shell geometry, fly chaetotaxy, fin shape and ray number in fishes, scale counts in squamate reptiles? Parasites' behavioral responses to hosts? Possible examples of many of these have been described (West-Eberhard 2003), but these and countless other taxonomically and/or ecologically important features have been little studied. 


\section{REFERENCES}

Aubret, F., and R. Shine. 2009. Genetic assimilation and the postcolonization erosion of phenotypic plasticity in island tiger snakes. Current Biology 19:1932-1936.

Bonduriansky, R. 2021. Plasticity across generations. In D. W. Pfennig, ed. Phenotypic Plasticity and Evolution: Causes, Consequences, Controversies. CRC Press, Boca Raton, FL.

Bonduriansky, R., and T. Day. 2009. Nongenetic inheritance and its evolutionary implications. Annu. Rev. Ecol. Evol. Syst. 40:103-125.

Bonduriansky, R., and T. Day. 2018. Extended Heredity: A New Understanding of Inheritance and Evolution. Princeton University Press, Princeton and Oxford.

Both, C., et al. 2006. Climate change and population declines in a long-distance migratory bird. Nature 441:81-83.

Bowler, P. J. 1989. Evolution: The History of an Idea. University of California Press, Berkeley.

Bradshaw, A. D. 1965. Evolutionary significance of phenotypic plasticity in plants. $A d v$. Genet. 13:115-155.

Chevin, L.-M., and A. A. Hoffmann. 2016. Evolution of phenotypic plasticity in extreme environments. Phil. Trans. R. Soc. 372:20160138.

Chevin, L.-M., R. Lande, and G. M. Mace. 2010. Adaptation, plasticity, and extinction in a changing environment: Towards a predictive theory. PLoS Biology 8:8.

Clausen, J., D. D. Keck, and W. M. Hiesey. 1940. Experimental studies on the nature of species. I. The effect of varied environments on western North American plants. Carnegie Institution of Washington, Pub. No. 520, 6:60-63.

Conover, D. O., and E. T. Schultz. 1995. Phenotypic similarity and the evolutionary significance of countergradient variation. Trends Ecol. Evol. 10:248-252.

Cook, S. A., and M. P. Johnson. 1968. Adaptation to heterogeneous environments. I. Variation in heterophylly in Ranunculus flammulus L. Evolution 22:496-516.

Corl, A., et al. 2018. The genetic basis of adaptation following plastic changes in coloration in a novel environment. Curr. Biol. 28:2970-2977.

Costa, J. T. 2021. "There is hardly any question in biology of more importance:" Charles Darwin and the nature of variation. In D. W. Pfennig, ed., Phenotypic Plasticity and Evolution: Causes, Consequences, Controversies. CRC Press, Boca Raton, FL.

Crean, A. J., et al. 2013. Adaptive paternal effects? Experimental evidence that the paternal environment affects offspring performance. Ecology 94:2575-2582.

Crispo, E. 2007. The Baldwin effect and genetic assimilation: Revisiting two mechanisms of evolutionary change mediated by phenotypic plasticity. Evolution 61:2469-2479.

Darwin, C. 1996 (1859). The origin of species (reprint of second edition). Oxford University Press, Oxford and New York.

de Jong, G., and R. H. Crozier. 2003. A flexible theory of evolution. Nature 424:16-17.

de Visser, J. A. G. M., et al. 2003. Perspective: Evolution and detection of genetic robustness. Evolution 57:1959-1972.

DeWitt, T. J., A. Sih, and D. S. Wilson. 1988. Costs and limits of phenotypic plasticity. Trends Ecol. Evol. 13:77-81.

Diamond, S. E., and R. A. Martin. 2021. Buying time: Plasticity and population persistence. In D. W. Pfennig, ed. Phenotypic Plasticity and Evolution: Causes, Consequences, Controversies. CRC Press, Boca Raton, FL.

Dobzhansky, Th. 1937. Genetics and the Origin of Species (First edition). Columbia University Press, New York.

Dobzhansky, Th. 1951. Genetics and the Origin of Species (Third edition). Columbia University Press, New York.

Dobzhansky, Th. 1970. Genetics of the Evolutionary Process. Columbia University Press, New York and London. 
Draghi, J. A., and M. C. Whitlock. 2012. Phenotypic plasticity facilitates mutational variance, genetic variance, and evolvability along the major axis of environmental variation. Evolution 66:2891-2902.

Falconer, D. S. 1981. Introduction to Quantitative Genetics (Second edition). Longmans, London.

Fisher, R. A. 1930. The Genetical Theory of Natural Selection. Clarendon Press, Oxford.

Fox, R. I., et al. 2019. Beyond buying time: The role of plasticity in phenotypic adaptation to rapid environmental change. Phil. Trans. R. Soc. B 374:220180174.

Futuyma, D. J. 2015. Can modern evolutionary theory explain macroevolution? pp. 29-85. In E. Serrelli and N. Gontier, eds., Macroevolution: Explanation, Interpretation and Evidence. Springer, Heidelberg.

Futuyma, D. J. 2017. Evolutionary biology today, and the call for an extended synthesis. Interface Focus 7:20160145.

Futuyma, D. J., and G. Moreno. 1988. The evolution of ecological specialization. Annu. Rev. Ecol. Syst. 19:207-233.

Futuyma, D. J., C. Herrmann, S. Milstein, and M. C. Keese. 1993. Apparent transgenerational effects of host plant in the leaf beetle Ophraella notulata (Coleoptera: Chrysomelidae). Oecologia 96:365-372.

Gavrilets, S., and S. M. Scheiner. 1993. The genetics of phenotypic plasticity. V. Evolution of reaction norm shape. J. Evol. Biol. 6:31-48.

Ghalambor, C. K., et al. 2007. Adaptive versus non-adaptive phenotypic plasticity and the potential for contemporary adaptation in new environments. Funct. Ecol. 21:394-407.

Ghalambor, C. K., et al. 2015. Non-adaptive plasticity potentiates rapid adaptive evolution of gene expression in nature. Nature 525:372-375.

Gilbert, J.-M. 2017. The flexible stem hypothesis: Evidence from genetic data. Dev. Genes Evol. 227(5):297-307.

Goldschmidt, R. 1935. Gen und Ausseneigenschaft. Z. Indukt. Abstamm. Vererbungsl. 69:38-131.

Gregor, J.W. 1956. Genotype-environmental interaction and its bearing on a practical problem of international interest. Proceedings of International Grassland Congress, Palmerston, New Zealand, pp. 202-211.

Grether, G. F. 2005. Environmental change, phenotypic plasticity, and genetic compensation. Am. Nat. 166:E115-E123.

Haldane, J. B. S. 1932. The Causes of Evolution. Longmans, Green \& Co., London.

Hardy, N. B. 2017. Do plant-eating insect lineages pass through phases of host-use generalism during speciation and host switching? Phylogenetic evidence. Evolution 71:2100-2109.

Hermisson, J., and G. P. Wagner. 2004. The population genetic theory of hidden genetic variation and genetic robustness. Genetics 168:2271-2284.

Ho, W.-C., and J. Zhang. 2019. Genetic gene expression changes during environmental adaptations tend to reverse plastic changes even after the correction for statistical nonindependence. Mol. Biol. Evol. 36:604-612.

Hoffmann, A. A., and P. A. Parsons. 1991. Evolutionary Genetics and Environmental Stress. Oxford University Press, Oxford.

Huxley, J. M. 1942. Evolution; The Modern Synthesis. Allen and Unwin, London.

Janz, N., and S. Nylin. 2008. The oscillation hypothesis of host-plant range and speciation, pp. 203-215. In K. Tilmon, ed., Specialization, Speciation, and Radiation: The Evolutionary Biology of Herbivorous Insects. University of California Press, Berkeley.

Kindred, B. 1965. Selection for temperature sensitivity in scute Drosophila. Genetics 52:723-728.

Kirkpatrick, M., and R. Lande. 1989. The evolution of maternal characters. Evolution 43:485-503.

Kirschner, M., and J. Gerhart. 2005. The Plausibility of Life. Yale University Press, New Haven, CT. 
Laland, K. N., et al. 2015. The extended evolutionary synthesis: Its structure, assumptions, and predictions. Proc. R. Soc. B 282:20151019. Doi:10.1098/rspb.2015.1019.

Lande, R. 2009. Adaptation to an extraordinary environment by evolution of phenotypic plasticity and genetic assimilation. J. Evol. Biol. 22:1435-1446.

Lande, R., and M. Kirkpatrick. 1990. Selection responses in traits with maternal inheritance. Genet. Res. 55:189-197.

Lawson, H. A., J. M. Cheverud, and J. B. Wolf. 2013. Genomic imprinting and parent-oforigin effects on complex traits. Nat. Rev. Genet. 14:609-617.

Ledón-Rettig, C. C., D. W. Pfennig, and E. J. Crespi. 2010. Diet and hormonal manipulation reveal cryptic genetic variation: Implications for the evolution of novel feeding strategies. Proc. R. Soc. B 277:3569-3578.

Levis, N. A., and D. W. Pfennig. 2021. Innovation and diversification via plasticity-led evolution. In D. W. Pfennig, ed., Phenotypic Plasticity and Evolution: Causes, Consequences, Controversies. CRC Press, Boca Raton, FL.

Levis, N. A., A. J. Isdaner, and D. W. Pfennig. 2018. Morphological novelty emerges from pre-existing phenotypic plasticity. Nat. Ecol. Evol. 2:1289-1297.

Lister, A. M. 2021. Phenotypic plasticity in the fossil record. In D. W. Pfennig, ed., Phenotypic Plasticity and Evolution: Causes, Consequences, Controversies. CRC Press, Boca Raton, FL.

Lynch, M., and W. Gabriel. 1987. Environmental tolerance. Am. Nat. 129:283-303.

Mather, K. 1953. Genetical control of stability in development. Heredity 7:297-336.

Mather, K. 1955. Response to selection: Synthesis. Cold Spring Harbor Symp. Quant. Biol. 20:158-165.

Mayor, S. J., et al. 2017. Increasing phenological asynchrony between spring green-up and arrival of migratory birds. Scientific Reports 7:1902. Doi: 10.1038/s41538-017-0045-z.

Mayr, E. 1959. Where are we? Cold Spring Harbor Symp. Quant. Biol. 24:1-14.

Mayr, E. 1963. Animal Species and Evolution. Belknap Press of Harvard University Press, Cambridge, MA.

Milkman, R. 1965. The genetic basis of natural variation, VI. Selection of a crossveinless strain of Drosophila by phenocopying at high temperature. Genetics 51:87-96.

Moczek, A. P., et al. 2006. When ontogeny reveals what phylogeny hides: Gain and loss of horns during development and evolution of horned beetles. Evolution 60:2329-2341.

Moran, N. A. 1992. The evolutionary maintenance of alternative phenotypes. Am. Nat. 139:971-989.

Mousseau, T. A., and C. W. Fox. 1998. Maternal Effects as Adaptations. Oxford University Press, Oxford and New York.

Murren, C. J., et al. 2015. Constraints on the evolution of phenotypic plasticity: Limits and costs of phenotype and plasticity. Heredity 115:293-301.

Noble, D. W. A., R. Radersma, and T. Uller. 2019. Plastic responses to novel environments are biased towards phenotype dimensions with high additive genetic variation. Proc. Nat. Acad. Sci. U. S. A. 116:13452-13461.

Nosil, P., and A. Ø. Mooers. 2005. Testing hypotheses about ecological specialization using phylogenetic trees. Evolution 59:2256-2263.

Orzack, S. H. 1986. Sex-ratio control in a parasitic wasp, Nasonia vitripennis. II. Experimental analysis of an optimal sex-ratio model. Evolution 40:341-356.

Paaby, A. B., and M. V. Rockman. 2014. Cryptic genetic variation: Evolution's hidden substrate. Nat. Rev. Genet. 15:247-258.

Pfennig, D. W. 2021. Key questions about phenotypic plasticity. In D. W. Pfennig, ed., Phenotypic Plasticity and Evolution: Causes, Consequences, Controversies. CRC Press, Boca Raton, FL.

Phillimore, A. B., et al. 2016. Passerines may be sufficiently plastic to track temperature-mediated shifts in optimum lay dates. Global Change Biol. 22:3259-3272. 
Pigliucci, M. 2010. Phenotypic plasticity, pp. 355-378. In M. Pigliucci, and G. B. Müller, eds., Evolution: The Extended Synthesis. MIT Press, Cambridge, MA and London.

Pigliucci, M., and G. B. Müller (eds.). 2010. Evolution: The extended synthesis. MIT Press, Cambridge, MA and London.

Prout, T. 1962. The effects of stabilizing selection on the time of development in Drosophila melanogaster. Genet. Res. 3:364-382.

Reeve, H. C. R. 1960. Some genetic tests on asymmetry of sternopleural chaeta number in Drosophila. Genet. Res. 1:151-172.

Rendel, J. M. 1959. Canalization of the scute phenotype of Drosophila. Evolution 13:425-439.

Rensch, B. 1959. Evolution above the Species Level. Columbia University Press, New York. (German original Neuere Probleme der Abstammungslehre, 1947.)

Roughgarden, J. 1979. Theory of Population Genetics and Evolutionary Ecology. MacMillan, New York.

Rutherford, S. L., and S. Lindquist. 1998. Hsp90 as a capacitor for morphological evolution. Nature 396:336-342.

Scheiner, S. 1993. Genetics and evolution of phenotypic plasticity. Annu. Rev. Ecol. Syst. 24:35-68.

Scheiner, S. M., and C. J. Goodnight. 1984. The comparison of phenotypic plasticity and genetic variation in populations of the grass Danthonia spicata. Evolution 38:845-855.

Scheiner, S. M. and N. A. Levis. 2021. The loss of phenotypic plasticity via natural selection: Genetic assimilation. In D. W. Pfennig, ed., Phenotypic Plasticity and Evolution: Causes, Consequences, Controversies. CRC Press, Boca Raton, FL.

Scheiner, S. M., M. Barfield, and R. D. Holt. 2017. The genetics of phenotypic plasticity. $\mathrm{XV}$. Genetic assimilation, the Baldwin effect, and evolutionary rescue. Ecol. Evol. 7:8788-8803.

Schlichting, C. D. 1986. The evolution of phenotypic plasticity in plants. Annu. Rev. Ecol. Syst. 17:667-693.

Schlichting, C. D. 2008. Hidden reaction norms, cryptic variation and evolvability. Ann. New York Acad. Sci. 1133:187-203. Doi: 10.1196/annals.1438.010.

Schlichting, C. D. and M. Pigliucci. 1998. Phenotypic Evolution: A Reaction Norm Perspective. Sinauer, Sunderland, MA.

Schluter, D. 1996. Adaptive radiation along genetic lines of least resistance. Evolution 50:1766-1774.

Schmalhausen, I. I. 1949. Factors of Evolution: The Theory of Stabilizing Selection. University of Chicago Press, Chicago, IL.

Schmid, B., and C. Dolt. 1994. Effects of maternal and paternal environment and genotype on offspring phenotype in Solidago altissima L. Evolution 48:1525-1549.

Schwander, T., and O. Leimar. 2011. Genes as leaders and followers in evolution. Trends Ecol. Evol. 26:143-151.

Scoville, A. G., and M. E. Pfrender. 2010. Phenotypic plasticity facilitates recurrent rapid adaptation to introduced predators. Proc. Nat. Acad. Sci. U. S. A. 107:4260-4263.

Semlitsch, R. D., R. N. Harris, and H. M. Wilbur. 1990. Paedomorphosis in Ambystoma talpoideum: Maintenance of population variation and alternative life-history pathways. Evolution 44:1604-1613.

Simpson, G. G. 1953. The Baldwin effect. Evolution 7:110-117.

Snell-Rood, E. C. and S. M. Ehlman. 2021. Ecology and evolution of plasticity. In D. W. Pfennig, ed., Phenotypic Plasticity and Evolution: Causes, Consequences, Controversies. CRC Press, Boca Raton, FL.

Snell-Rood, E. C., et al. 2018. Mechanisms of plastic rescue in novel environments. Annu. Rev. Ecol. Evol. Syst. 49:331-354. 
Socolar, J. B., et al. 2017. Phenological shifts conserve thermal niches in North American birds and reshape expectations for climate-driven niche shifts. Proc. Nat. Acad. Sci. U. S. A. 114:12976-12981.

Standen, E. M., T. Y. Du, and H. C. E. Larsson. 2014. Developmental plasticity and the origin of tetrapods. Nature 513:54-57.

Stearns, S. C. 1983. The evolution of life history traits in mosquitofish since their introduction to Hawaii in 1905: Rates of evolution, heritabilities, and developmental plasticity. Am. Zool. 23:65-75.

Stearns, S. C., and J. C. Koella. 1986. The evolution of phenotypic plasticity in life-history traits: Predictions of reaction norms for age and size at maturity. Evolution 40:893-913.

Stebbins, G. L. 1950. Variation and Evolution in Plants. Columbia University Press, New York.

Storz, J. F., and G. R. Scott. 2019. Life ascending: Mechanism and process in physiological adaptation to high-altitude hypoxia. Annu. Rev. Ecol. Evol. Syst. 50:503-526.

Taper, M. L., and T. J. Case.1985. Quantitative genetic models for the coevolution of character displacement. Ecology 66:35-371.

Thoday, J. M. 1953. Components of fitness. Symp. Soc. Exp. Biol. 7:96-113.

Turesson, G. 1922. The genotypical response of the plant species to the habitat. Hereditas 3:211-350.

Van Buskirk, J., and U. K. Steiner. 2009. The fitness costs of developmental canalization and plasticity. J. Evol. Biol. 22:852-860.

van Tienderen, P. H. 1991. Evolution of generalists and specialists in spatially heterogeneous environments. Evolution 45:1317-1331.

Via, S., and R. Lande. 1985. Genotype-environment interaction and the evolution of phenotypic plasticity. Evolution 39:505-522.

Waddington, C. H. 1942. The canalization of development and the inheritance of acquired characters. Nature 150:563-565.

Waddington, C. H. 1952. Selection of the genetic basis of an acquired character. Nature 169:278.

Waddington, C. H. 1953a. Genetic assimilation of an acquired character. Evolution 7:118-126.

Waddington, C. H. 1953b. The Baldwin effect, genetic assimilation and homeostasis. Evolution 7:386-387.

Wagner, G. P. 2014. Homology, Genes, and Evolutionary Innovation. Princeton University Press, Princeton and Oxford.

Wagner, G. P., G. Booth, and H. Bagheri-Chaichian. 1997. A population genetics theory of canalization. Evolution 51:329-347.

West-Eberhard, M.-J. 1986. Alternative adaptations, speciation and phylogeny (a review). Proc. Nat. Acad. Sci. U. S. A. 83:1388-1392.

West-Eberhard, M.-J. 1989. Phenotypic plasticity and the origins of diversity. Annu. Rev. Ecol. Syst. 20:249-278.

West-Eberhard, M.-J. 2003. Developmental plasticity and evolution. Oxford University Press, Oxford and New York.

Wolf, J. B., E. D. Brodie III, J. M. Cheverud, A. J. Moore, and M. J. Wade. 1998. Evolutionary consequences of indirect genetic effects. Trends Ecol. Evol. 13:64-69.

Woltereck, R. 1909. Untersuchungen über Artveränderung, speziell über das Wesen quantitativer Artunterschiede bei Daphniden. Versuche Deutsche Zoologische Gesellschaft 19:110-172.

Wright, S. 1931. Evolution in Mendelian populations. Genetics 16:97-159. 